The Geneva Papers on Risk and Insurance, 17 (No. 65, October 1992), 485-498

\title{
Using Economic Incentives to Regulate the Municipal Solid Waste Stream
}

\author{
by Peter S. Menell *
}

\section{Background}

Over the past decade, the rising municipal solid waste stream has emerged as one of the most pressing environmental problems throughout the industrialized world. Landfill space is running out rapidly in many areas; Holland, for example, has essentially exhausted its capacity. ${ }^{1}$ Moreover, many old landfills are leaking hazardous materials into groundwater and in part as a result of these leaks, many communities have effectively blocked the construction of new landfills. With landfill capacity on the decline, some communities have turned to incineration as a means of solving their solid waste problems. Widespread use of incineration, however, may exacerbate conventional air pollution in already polluted areas, significantly increase the emissions of hazardous air pollutants, and produce another solid waste problem: disposal of hazardous incinerator ash. These considerations have led many jurisdictions to reject the siting of new incinerators. ${ }^{2}$ These developments indicate that serious resource allocation problems exist in the manner in which industrialized nations are regulating the municipal solid waste stream.

\subsection{Dimensions of the solid waste stream}

The municipal solid waste stream comprises the complex process by which wastes move from raw materials to reuse, recovery, or disposal. Along the way, the stream is shaped by numerous manufacturer, consumer, waste processor, and municipal decisions. The waste stream begins with raw material and product design choices by manufacturers. These choices reflect consumer preferences for products and packaging, as well as the

* Acting Professor of Law, University of California at Berkeley School of Law (Boalt Hall). S. B., Massachusetts Institute of Technology, 1980; J. D. Harvard Law School, 1986; Ph. D. (economics), Stanford University, 1986. I wish to thank Michael Faure and an anonymous referee for helpful comments.

1 Throwing Things Away, The Economist 13 (October 5, 1991). In the United States, it is estimated that more than one-third of the nation's landfills will be full by 1992. EPA, The Solid Waste Dilemma: An Agenda for Action 8 (1989); see also Glenn \& Riggle, Biocycle Survey: Where Does the Waste Go? 30 Biocycle 34, 37 (April 1989).

2 See Throwing Things Away, The Economist 13 (October 5, 1991) (noting that the Swiss have repeatedly voted down new incinerators). See also Massachusetts: State Announces 10-Point Waste Plan, Moratorium on New Garbage Incinerators, 19 Env't Rep. (BNA) 1436 (November 11, 1988). 
availability and cost of materials. Consumers influence the municipal solid waste stream both through their purchasing decisions and, later, through their choices regarding disposal. Wastes that consumers reuse or compost ${ }^{3}$ do not reach the disposal end of the municipal solid waste stream. Wastes that consumers separate can be recycled; some valuable wastes that consumers do not separate, such as ferrous metals, can feasibly be separated for recycling after they reach a waste transfer station or disposal site.

The municipal solid waste stream consists significantly of paper and paperboard, glass, metals, plastics, and food and yard wastes. Other components include rubber, leather, textiles, and wood. Constituents of the municipal waste stream range anywhere from a crumpled piece of paper to a discarded refrigerator.

Many of the components of the municipal solid waste stream, when separated and recycled, have significant salvage values. In addition, many wastes (particularly plastics, rubber, textiles, wood, and paper products) have high energy contents, which can be extracted through modern incineration technologies ${ }^{4}$ The components of the waste stream also vary widely in their volume ${ }^{5}$ and bio- and photodegradability. ${ }^{6}$ Food and yard wastes degrade rapidly when exposed to high oxygen environments. By contrast, most plastics do not degrade, even in the presence of light and oxygen. Although most of the municipal waste stream is not toxic, a number of hazardous household materials, including batteries, inks, used oils, antifreeze, paints and paint solvents, insecticides, and herbicides, find their way into the municipal solid waste stream. These substances can cause serious harm to both humans and ecosystems if not disposed properly.

${ }^{3}$ Composting refers to controlled biological decomposition of organic wastes (such as food, grass clippings, and leaves) under aerobic (i.e., in the presence of oxygen) conditions. Composting produces materials such as humus and mulch, which can be used to enrich soils.

${ }^{4}$ Modern incineration technologies both reduce the volume of waste by 60 to 90 percent and generate significant amounts of industrial steam, electricity, or fuel. The efficiency and environmental effects of these technologies depend critically upon the energy content and toxicity of the waste stream.

${ }^{5}$ For example, plastics have significantly lower densities than the average density of landfilled materials, hence they take up significantly more volume for a given weight. Plastic products, however, tend to have much lower weight per container than other packaging materials. Moreover, advances in plastics manufacturing have substantially reduced the amount of plastic needed to package a given amount of material. Therefore, even though plastics use has grown significantly over the past two decades, the percentage of landfill space devoted to plastics has remained relatively constant at about 14 percent because newer lighter plastics use less raw material and are more compactable. By contrast, the amount of landfill space devoted to paper has increased from 20 percent to 55 percent over this same period. See Rathje, Municipal Refuse: Are Misconceptions Misleading Policymakers? (Briefing, Senate Caucus Room, Feb. 22, 1989) (transcript available from the Environmental and Energy Study Institute, Washington, D.C.).

6 These latter attributes are particularly important with regard to littering. Littered wastes disrupt natural ecosystems and are aesthetically unpleasing in natural settings. In addition, some plastic litter poses a particular threat to marine mammals and birds.

Degradability is not, however, a desirable attribute for inost properly disposed wastes. Recycled materials reenter the stream of commerce as useful products. Therefore, natural degradability can be undesirable to the extent it reduces the recyclability and durability of products. Incinerated wastes are largely destroyed through high temperature combustion. Therefore, non-biodegradability does not present an environmental problem, except to the extent it is related to the amount of residual ash. High moisture content, which is typical of many naturally degradable wastes, reduces the efficiency of incineration. And contrary to some popular perceptions, landfills are typically designed to slow or prevent degradation so as to discourage the leaching of contaminants into groundwater and the formation of combustible gases. 
Channelling the various components of the municipal solid waste stream to their most valued ends - whether reuse, recycling, composting, incineration, or the landfill - is greatly complicated by the tremendous heterogeneity of the waste stream. Unlike many types of industrial, mining, and agricultural wastes - for which there is usually large, relatively homogeneous quantities in a well-defined area - each accumulation point of the municipal solid waste stream contains relatively small amounts of diverse, mixed materials. Consequently, there are significant tradeoffs between the gain to channelling wastes to their most valuable disposal or resource recovery alternative and the costs of the channelling effort.

The United States relies most heavily upon mass disposal of mixed wastes, with $83 \%$ of its municipal solid waste buried in landfills, $11 \%$ recycled, and $6 \%$ burned in incinerators. ${ }^{7}$ Despite this tremendous overall reliance upon landfill, there is significant regional variation within the United States attributable to population density, the cost and availability of land for waste disposal, hydrogeologic and geographic conditions, social attitudes toward the environment, economic characteristics, and municipal solid waste policies. ${ }^{8}$ Compared to other industrialized nations, the United States has performed poorly at channelling wastes to their most valued uses. Japan recycles $50 \%$ of its municipal solid waste, incinerates $23 \%$, and landfills only $27 \%$; West Germany landfills $55 \%$ of its municipal solid waste, incinerates $30 \%$, and recycles $15 \% .^{9}$

\subsection{The haphazard policy response}

For most households, there has been little incentive to reduce the amount of solid waste they generate or to recycle what they do generate. ${ }^{10}$ The cost of throwing away an additional item of refuse has been (and in many places continues to be) zero. In these communities, residents need merely place their empty bottles and cans, lawn clippings, and

7 See Franklin Associates, Ltd., Characterization of Municipal Solid Waste in the United States, 1960 to 2000 (Update 1988) (March 30, 1988) (prepared for EPA).

8 The solid waste crisis is most acute in the Northeast, with landfill tipping fees, the disposal charge per ton, as high as $\$ 135$, and some communities forced to ship wastes elsewhere because their landfills have reached capacity. As a result, the Northeast has turned increasingly to incineration, with Connecticut leading the way by incinerating $66 \%$ of its municipal solid waste. By contrast, landfill tipping fees in the West are typically less than $\$ 30$ per ton and as low as $\$ 5$ per ton in some communities. Notwithstanding the availability of landfill space in the West, Washington and Oregon lead the United States in recycling, achieving recovery rates of $22 \%$ and $17 \%$, respectively. See Biocycle Survey, supra note 1 , at 35 .

9 A. Hershkowitz \& E. Salerni, Garbage Management in Japan (INFORM 1987) (cited in National Solid Wastes Management Association, Resource Recovery and the Environment (1989)) ; Federal Environmental Protection Agency (UBA), Berlin, 1987 (cited in National Solid Wastes Management Association, Resource Recovery and the Environment (1989)).

${ }^{10}$ Even for those households that are willing to purchase environmentally safe products without any direct financial incentive to do so, it is difficult to know which products to buy. For example, biodegradable products are often portrayed as environmentally sound. As discussed earlier, however, such claims are doubtful. See note 6.

Which products are most environmentally sound depends not only on what the remaining refuse is made of, but also how it will be deposed. Thus, although plastics are particularly detrimental if they are littered because they do not degrade and they are often costly to recycle because of the difficulty of segregating resin types and the limitations of plastics recycling technologies, they are stable in landfills and produce large amounts of energy in modern incinerators. Plastics may present a problem in incinerators, however, if their fixatives and labels contain heavy metal inks or other contaminants. Glass, by contrast, can be easily recycled and is also stable in landfills, but because it is inorganic, produces little energy in incinerators and reduces the efficiency of incinerating other materials by lowering the burn temperature. 
old newspapers in a trash chute or at the curbside. Such refuse "disappears" when the municipality (or its contractor) picks it up. Although the costs of refuse removal and disposal are significant, these services are typically borne by consumers only indirectly by way of a fixed disposal charge or an annual property tax assessment. Given the largely hidden cost of municipal solid waste disposal in the United States, it is not hard to understand why the "throw-away" ethic has thrived.

Furthermore, industry often lacks adequate incentives to use recycled materials. Within the United States, for example, virgin materials that compete with recycled materials, such as timber and petroleum products, benefit from tax and natural resource subsidies, including below cost timber sales and oil and mining depletion allowances, among others. Moreover, since the environmental costs of landfill have been seriously underpriced $^{11}$ and communities have not offered recyclers the avoided cost of solid waste diverted from landfills and incinerators, users of recycled materials do not share adequately in the disposal cost savings that they bring about.

Although late in responding to solid waste problems, many nations and communities have begun to take action. Among the policies currently being pursued are a variety of command and control strategies to limit waste and increase recycling including mandatory separation by households of one or a few categories of solid waste, prohibitions on the disposal of specific items such as yard clippings in landfills, and bans on packaging and products, such as plastic food containers and disposable diapers. In addition, many jurisdictions have enacted deposit-refund systems for beverage containers.

Although these policies respond to some of the symptoms of the solid waste "crisis", they fail to systematically remedy the distorted incentives that underlie consumer and manufacturer behavior. Indeed, in some cases, these failures exacerbate preexisting distortions. For example, a requirement that consumers separate glass containers encourages consumers to purchase more products packaged in materials that may have higher social disposal costs in order to avoid the separation requirement. Moreover, mandatory separation has not always led to substantially increased recycling. Without adequate recycling capacity and markets for recycled materials, many communities that have implemented mandatory separation requirements have had to store or even landfill separated newsprint. ${ }^{12}$

In other cases, the use of ad hoc adjustments to an inherently flawed system may create new distortions. For example, a ban on certain types of packaging or products (such as disposable diapers) prevent consumers with strong preferences for such packaging or products (and a willingness to pay for their full disposal cost) from obtaining them, without having a significant effect on the waste stream.

Even deposit-refund systems, which do encourage separation of beverage containers through price incentives, fail to provide correct incentives for purchasing and disposal. ${ }^{13}$

11 Landfills are inadequately regulated in many areas. See Organization for Economic Cooperation and Development (OECD), The State of the Environment: 1985165.

12 See Paper Recycling: For Now, Too Much of a Good Thing, New York Times, September 6 , 1989, page A 19; Cutler, Recycling Markets: Is Mandated Recycling Possible? Solid Waste \& Power 54 (August 1988).

${ }_{13}$ See Menell, Beyond the Throw-Away Society: An Incentive Approach to Regulating Municipal Solid Waste, 17 Ecology Law Quarterly 655 (1990). 
By charging the same amount for glass, metal, and plastic containers, such laws do not encourage consumers to choose the container with the lowest social disposal cost. Moreover, by equating the deposit and refund amounts, such policies fail to reflect the true social gain from recycling (unless it happens to be zero on net). Furthermore, by requiring consumers to deliver separated containers to redemption centers rather than providing curbside pick-up of separated containers, deposit-refund policies create needless inconvenience. ${ }^{14}$ Since most municipalities already collect mixed refuse at the curbside, there are significant economies from collecting separated items at the curbside as well.

\section{The role of economic incentive systems in regulating the municipal solid waste stream}

Two related problems underlie the municipal solid waste crisis. First, many communities do not utilize an appropriate mix of environmentally sound and economically efficient resource recovery and disposal technologies. Second, consumers' purchasing and disposal decisions are not adequately sensitive to the environmental costs of waste disposal.

Unfortunately, because of the tremendous heterogeneity of the land use patterns, population density, transportation systems, industrial base, natural resources, hydrogeology, and air flow patterns of communities in the industrialized world, there is no one correct disposal technology or mix of technologies for all communities. For example, landfill may still be an environmentally superior disposal option for some waste in sparsely populated arid regions, while being prohibitively expensive in densely populated areas where land availability and groundwater conditions are less favorable. As another example, given transportation costs, the cost of virgin materials, and the industrial base, some regions may support types of recycling that would not be viable elsewhere. In any case, the optimal mix of disposal technologies for any particular community depends upon a variety of dynamic factors that vary significantly across communities.

Similarly, because of the heterogeneity of consumers and living patterns, there is rarely one ideal packaging option and disposal choice for all households. For example, some families may find disposable diapers indispensable, while others can make do with cloth. ${ }^{15}$ Public policies regulating municipal solid waste must be sensitive to the heterogeneity of communities, resources, and people. These factors explain why command and control type policies, such as product bans, are poorly suited to addressing the municipal solid waste crisis.

Economic incentive systems, because of their inherent flexibility, provide the ideal structure for regulating the complex municipal solid waste stream. Internalizing the environmental costs of disposal technologies and fostering the development of recycling markets are the keys to achieving an environmentally sound and sustainable mix of resource recovery and disposal technologies. This approach would also create strong incentives for the development and diffusion of better recycling and waste disposal technologies.

${ }^{14}$ See Porter, A Social Benefit-Cost Analysis of Mandatory Deposits on Beverage Containers, 5 J. Envtl. Econ. \& Mgmt. 351 (1978) (finding that the social desirability of mandatory deposit laws depend critically on the value of the time it takes consumers to return empty containers).

15 It is far from clear whether disposable or cloth diapers are more environmentally sound. Although disposable diapers consume more raw materials and result in greater solid waste, cloth diapers consume significantly more energy and water and cause greater water pollution. See Holusha, Diaper Debate: Cloth or Disposable? New York Times, July 14, 1990, page 16. 
Furthermore, just as charging for the production costs of goods at the grocery store check-out counter encourages consumers to economize on their purchasing decisions, charging the true social costs of refuse disposal and offering the net salvage value of separated wastes would encourage consumers to make purchasing and disposal decisions that are sensitive to the environment. And since consumer preferences for products and packaging form the basis for product design decisions by manufacturers, economic incentive systems would encourage manufacturers to develop packaging and products that can be more readily reused and recycled where reuse and recycling are advantageous. In addition, by imposing the costs of waste disposal upon those responsible for its generation, economic incentive systems would more equitably distribute the costs of preventing environmental degradation.

Unlike charging for the production costs of goods at the grocery store check-out counter, however, it is difficult to know the social disposal cost of what the consumer will throw away at the time she purchases a product. This cost depends upon how the consumer uses and disposes of such refuse. If she reuses the leftover container, then the social disposal cost is minimal. If she separates the container, then the social disposal cost is the net salvage value of the recycled container (i. e., the market price of recycled material less the costs of collection and recycling). If it goes to an incinerator, then the social disposal cost is the net value of the energy recovered (i. e., the market price of energy generated less the costs of collection and incineration, including the costs of hazardous air emissions and hazardous ash). If it goes to a landfill, then the social disposal cost is the cost of collection plus the value of the space occupied and the costs of operating the landfill. In addition, many items of refuse are not purchased at the grocery store, such as most newspapers and yard clippings. Thus, charging for the social costs of disposal is more complicated than charging for the costs of producing a grocery item.

Nonetheless, a variety of straightforward economic incentive systems are capable of charging consumers for reasonable approximations of the environmental costs of their purchasing and disposal decisions. Some communities have instituted curbside charges for mixed refuse. These policies charge households for the amount of mixed refuse that they leave at the curbside based on the costs of collection and disposal. They create a strong incentive for households to separate the recyclable components of their refuse, especially if separated items are picked up for free. They also create a strong incentive to reduce the amount of waste generated, either by reusing products and containers or composting yard and food wastes. Since yard wastes alone account for more than 20 percent of municipal solid waste in the United States (and an even larger percentage in suburban communities where curbside charges are most feasible), curbside charge policies can have an enormous impact on the amount of the waste stream reaching landfills and incinerators. ${ }^{16}$ Curbside charge policies also create an incentive for household members to purchase products and packaging that are less costly to dispose or can be reused or composted. Furthermore, they create incentives for recycling entrepreneurs, such as salvage companies and firms making natural fertilizers from compost, to collect wastes directly from households, thereby diverting resources from landfills and incinerators.

${ }^{16}$ Because of their relatively low energy content and high moisture content, yard wastes inhibit the efficiency of incineration. 
A retail disposal charge based on the expected social disposal cost ${ }^{17}$ of retail products and their packaging would also improve consumers' purchasing incentives. If separately printed on store shelves and product labels and separately calculated on cash register receipts, such charges would provide consumers with tangible evidence of the private and social cost of their purchasing decisions. As a result, such charges would provide direct incentives for manufacturers to develop and offer products and packaging resulting in lower disposal costs. For example, in a community that uses waste-to-energy incineration, such surcharges would favor materials with high energy values and penalize packaging that contains hazardous materials, such as labels made of heavy metal inks, that might escape into the air or contaminate ash. Moreover, this system would create an incentive for manufacturers and retailers to encourage waste separation and recycling because higher separation participation rates and net salvage values would reduce expected social disposal cost, thereby lowering the surcharges on products. Although retail charges only indirectly encourage better disposal decisions through manufacturer, retailer, and general community pressure to keep disposal surcharges down, the retail disposal charge can be combined with the curbside charge to create even more precise purchasing and disposal incentive effects. ${ }^{18}$

In order to be feasible, however, the costs of implementing economic incentive systems must not outweight the environmental benefits. The experience of the communities that have experimented with these approaches, as well as a variety of technological innovations, suggest that economic incentive systems could be feasibly implemented.

The costs of implementing the curbside charge policy are similar to the costs of charging for electricity, natural gas, and water by public utilities. The usage of these services must be monitored. In the context of these traditional public utilities, the principal transaction costs are meter reading and billing. These costs have been substantially reduced with the advent of advanced data processing and mailing technologies. With the curbside charge policy, trash collectors would have to measure the weight or volume of the mixed items and load separated items into a few categorized bins (e.g., paper, glas, metal, plastic). With existing garbage truck design, this would be quite costly. It would be possible, however, to design vehicles with multiple bins for separated materials ${ }^{19}$ and scales (or other devices) for measuring the weight or volume of mixed refuse. On-board computers programmed with codes for each household on a daily run could calculate the refuse charge for particular households. At the end of a daily run, this data could be "dumped"

${ }^{17}$ Expected social disposal cost for a particular product is simply the percentage of that material that is separated times the net salvage value of recycling that amount of material plus the percentage of that material that is disposed in mixed refuse times the social disposal cost of landfilling (or incinerating, depending on the disposal technology of the community) that amount of material. For example, for a glass container weighing 1 pound in a community that separates $40 \%$ of its glass containers and landfills what is not separated, the expected social disposal cost would be .4* $(1 \mathrm{lb}$.) * (net salvage value of glass per lb.) $+.6^{*}(1 \mathrm{lb} .)^{*}$ (social disposal cost of disposing $1 \mathrm{lb}$. of glass in the community's landfill). The derivation of this charge is discussed further in Menell, Optimal MultiTier Regulation: An Application to Municipal Solid Waste, Law \& Economics Working Paper Series, University of California at Berkeley School of Law (September 1991).

18 See Menell, supra note 13.

${ }_{19}$ Multiple bin vehicles are now in use many communities. See e.g., Institute for Local SelfReliance, Directory of Waste Utilization Technologies in Europe and the United States (1989). 
into a main computer which prepared customer bills to be sent out on a monthly basis. As these technologies continue to develop, it might even be possible to develop a system that credited households for the weight or volume of separated items (based on net salvage values). Such a system would provide added incentive for households to separate valuable wastes. ${ }^{20}$

A number of communities have developed less precise, although less costly means of charging consumers for their mixed refuse. Seattle, Washington and a number of other communities in the United States have introduced curbside charges by billing households for the number and size of trash receptacles that they use. ${ }^{21} \mathrm{~A}$ more effective and simpler way of implementing the curbside charge is to require households to dispose mixed refuse in specially priced and designated trash bags sold by the community. ${ }^{22}$ This approach is currently in use in Perkasie, Pennsylvania, a suburban community of 6,500 people. ${ }^{23}$ Perkasie also provides curbside pick-up of aluminium beverage cans, glass, cardboard, and newspapers. From 1987 (the year before the program was implemented) to 1988 , the total amount of mixed solid waste collected in Perkasie fell from 2,573 tons to 1,038 tons, representing a $59 \%$ reduction. This resulted in a saving of more than $\$ 90,000$ in direct disposal costs (using Perkasie's 1988 tipping fee of $\$ 59$ per ton). In addition, since much of the reduced tonnage was attributable to greater separation of recyclable wastes, the town earned $\$ 15,456$ from the sale of aluminium and paper. On the cost side, the 1988 worker-hours for loading separated and mixed wastes $(2,781$ hours $)$ increased by only $18 \%$ over the average for 1985 to 1987 (2,273 hours). The full capital cost of the program (including a recycling trailer, modifications to the refuse vehicle, and recycling buckets) was less than $\$ 25,000$. The cost of separation borne by residents aside, the program has been an overwhelming success both financially ${ }^{24}$ and in terms of reducing municipal solid waste.

${ }^{20}$ Adoption of curbside charge policies might encourage illegal dumping or, in the case of separated refuse for which credits are available, theft of refuse. A number of factors, however, suggest that these problems will not seriously detract from the desirability of curbside charge policies. First, unlike with hazardous waste, municipal solid waste has negligible toxicity. Therefore, the social costs of illegal dumping of municipal solid waste are not enormous. The major social cost is aesthetic and not endangerment to health. Moreover, the clean-up costs of illegally disposed municipal solid waste are not likely to be anywhere near the costs of cleaning up improperly disposed hazardous wastes. Second, the level of charges are relatively modest in comparison to the inconvenience of illegal dumping. Third, illegally dumped mixed refuse will tend to contain, thanks to the enormous quantity of junk mail, clear indications of the culprit. Hence, effective enforcement of illegal disposal would be possible. Nonetheless, illegal disposal and the costs of enforcement would add to the costs of curbside charge policy and therefore should be considered carefully in policy design.

${ }^{21}$ Volume-based charges are also levied upon approximately $5 \%$ of households in France. See OECD, Economic Instruments for Environmental Protection 53-54 (1989).

${ }^{22}$ This approach is more effective than the Seattle per can charge because consumers are not registered for a specific number of cans per week. Whereas Seattle households have an incentive to fill each can to the brim (because the additional charge is zero), houscholds in "per bag" communities can simply put out fewer bags in a given week.

23 See Institute for Local Self-Reliance, Beyond 25 Percent: Materials Recovery Comes of Age $47-55$ (1989).

24 Overall, the town paid $40 \%$ less for garbage disposal than a year earlier. Paul, Pollution Solution: Pennsylvania Town Finds Way to Get Locals to Recycle Trash, Wall Street Journal, June 2, 1989, page 1. 
The retail disposal charge would be more complicated to implement, although recent advances in scanning technology and the widespread adoption of the Universal Product Code (bar codes) for identifying retail items suggest that this economic incentive system would also be feasible. Optical scanners at retail check-out counters read bar codes to determine the particular product being purchased. A computerized cash register looks up the price assigned to each product and any applicable taxes and rings it up on the consumer's bill. This system could be used to assign individualized disposal charges to all retail products by entering data into the computerized cash register on each product's composition of disposable materials, the recycling rate for different disposable materials, and the true social disposal costs for different materials. The principal hurdles to the implementation of this policy are gathering this data and coordinating policies across neighboring communities. ${ }^{25}$

\section{The federal role in regulating the municipal solid waste stream}

Due to the tremendous heterogeneity of the factors determining the size and environmental effects of the solid waste stream, uniform national regulatory policies for municipal solid waste would result in serious misallocations of resources. Government policy should be sensitive to the diversity of demographic, ecological, hydrogeologic, economic, and political factors at the local level. Therefore principal responsibility for solid waste policy should reside at the local level. Nonetheless, federal governments have an important role to play in setting regulatory policy because of their unique abilities to regulate national raw material and product markets, conduct research and process information centrally, and influence market development through procurement and other policies.

\subsection{Fostering an appropriate mix of resource recovery and disposal technologies}

As suggested above, the present market and regulatory structure systematically distorts the choice among resource recovery and disposal technologies. The landfilling of wastes tends to be underpriced because environmental regulation is inadequate. Moreover, the cost of landfilling is not transmitted to waste generators because many jurisdictions use average rather than marginal cost pricing. Thus, many households and businesses have little or no incentive to reduce the amount of waste that they send to landfills. On the other hand, recycling industries are hindered by having to compete with subsidized virgin materials, poor solid waste management policies that often do not enable them to realize the cost savings from diverting refuse from landfills, and hesitancy on the part of manufacturers and consumers to use recycled materials and products. In order to achieve an appropriate mix of resource recovery and disposal technologies, government policies should be directed at ensuring that the social costs of resource recovery and disposal technologies are properly reflected in market prices and promoting the development of recycling markets.

25 Although a growing proportion of retail sales are facilitated by optical scanning, currently more than $60 \%$ of retail grocery sales within the United States, an additional problem is raised by the fact that not all retail establishments use scanning technology. Municipalities can avoid bestowing a competitive advantage on these merchants by imposing an average disposal surcharge on their retail sales. Furthermore, as the cost of scanning equipment continues to fall with advances in computer technology, this problem will become less significant as more merchants adopt optical scanners. 


\subsubsection{Correcting distortions in the pricing of disposal and resource recovery technologies}

Federal governments can play an important role is ensuring that the pricing of landfill and incineration reflect environmental costs through their regulatory authority over disposal technologies. At present, however, federal environmental standards for landfill and incineration are inadequate in many nations. Moreover, where adequate standards exist, enforcement is often lax. Therefore, as a first step toward improving the pricing of disposal technologies, federal governments should ensure that adequate environmental standards are established for disposal technologies and allocate adequate resources for the enforcement of such standards.

In addition, federal governments should play a significant role in assisting local agencies in planning and pricing disposal and resource recovery technologies. Many municipal governments lack the resources and expertise required to conduct systematic and comprehensive research on the myriad environmental and economic issues involved in sound solid waste planning and management. Federal governments should develop central regulatory bodies capable of providing guidance on solid waste policy to the appropriate local authorities. Such regulatory bodies should fund research and collect information on the social costs of alternative disposal and resource recovery technologies in various hydrogeologic, land use, industrial, and demographic settings and act as information clearinghouses. They should also develop a team of solid waste planning and management experts who would be available to local solid waste planning authorities.

As the cornerstone to an economic approach to guiding solid waste planning and management, federal governments should encourage the use of "avoided cost" pricing of resource recovery technologies. At present, many municipalities expect recyclers to pay for separated wastes. Because of limited processing capacity and lagging demand for recycled materials, however, some separated wastes have a negative value. As long as this value is greater than the cost of disposal plus any additional cost of collecting separated wastes, municipalities should be willing to pay recyclers the disposal costs (net of added separation costs) that would be avoided by diverting wastes from landfill or incineration. For example, if it would cost a community $\$ 100$ per ton to landfill newspapers and an additional $\$ 20$ per ton to collect separated newspapers, then the community should be willing to pay as much as $\$ 80$ per ton to a recycler to accept separated newsprint. ${ }^{26}$ In this way, recycling industries would share in the social savings from reducing the use of disposal technologies, thereby lowering the cost of recycled materials.

\subsubsection{Promoting recycling markets}

Even after the pricing of disposal and resource recovery technologies are corrected to reflect true social costs, recycling technologies often face another significant impediment to development: tax and resource development subsidies for virgin materials. Federal governments should eliminate these distortions as expeditiously as possible.

Once the environmental costs of disposal are properly reflected in solid waste planning decisions and subsidies to competing materials are removed, market forces will be the principal driving force toward an appropriate mix of resource recovery and disposal technologies. Nonetheless, federal governments can still play an important role in improving the operation of recycling markets.

${ }^{26}$ Since recycling markets are reasonably competitive, municipalities would likely not have to pay their full break-even price to divert separated wastes from disposal technologies. 
The growth of recycling markets will be inhibited by the time that it takes for new information about materials to be disseminated and the lag inherent in business planning cycles, including the time needed to retrofit manufacturing processes to better utilize recycled materials. The environmental benefits of a better mix of disposal and resource recovery technologies, however, must await the increased use of recycled materials. The federal government, therefore, should implement a number of policies to expedite this transition.

Most directly, because of their research and information processing capabilities, federal governments should provide manufacturers and consumers with current information about the relative merits of recycled and virgin materials. At present, many manufacturers and consumers are reluctant to purchase recycled materials because of concerns about inferior and inconsistent quality. These concerns can be alleviated through the development of national quality standards for recycled materials. Federal governments should work with recycling industries to develop these standards, through either industry consensus or national and international standard setting bodies. In addition, federal authorities should identify manufacturing sectors that would benefit from utilizing more recycled materials and encourage their adoption of such materials. Limited funds could be made available to selected companies to cover the costs of conducting comparisons with virgin materials.

Along these same lines, because of their role as major purchasers of raw materials and products, federal governments should implement procurement guidelines that place recycled materials and products on at least equal footing with virgin materials. Such guidelines should emphasize function, especially where the aesthetic quality of recycled materials can be expected to improve as recycled technologies advance. In addition, effective enforcement mechanisms should be established for ensuring compliance with these guidelines. One such mechanism would be to allow recycling companies that lose bids for purchases above some minimum size to challenge procurement decisions favoring virgin materials of comparable quality (based on the guidelines) and price. To further ensure compliance, those who make successful challenges should be entitled to damages for lost or delayed sales, attorney fees, and other appropriate costs.

Although regulatory policy should be directed foremost toward attaining economically viable recycling industries, a variety of factors justify implementing subsidies encouraging the use of recycled materials and products, especially during a transitional period. Where swift elimination of subsidies for virgin materials is politically infeasible, compensating subsidies for recycling industries should be established so as to place recycled materials on a level playing field with virgin materials.

Subsidies for recycled materials are also justified because recycling technologies for many materials use significantly less energy and water resources and result in less pollution than their virgin counterparts. ${ }^{27}$ For example, the production of aluminium from scrap uses 90 to 97 percent less energy and results in 95 percent less air pollution and 97 percent less water pollution than production from virgin resources. Paper production from waste paper

27 See Pollock, Mining Urban Wastes: The Potential for Recycling (Worldwatch Paper 76, April 1987); Letcher \& Sheil, Source Separation and Citizen Recycling, in E. Robinson (ed.), The Solid Waste Handbook (1986). 
uscs 23 to 74 percent less energy and 58 percent less watcr than production for timber; recycled paper results in 74 percent lcss air pollution and 35 percent less water pollution.

Carefully tailored subsidies for the usc of recycled materials, therefore, would scrve the goals of energy conservation and reducing pollution. Among the ways of subsidizing recycling would bc to incorporate a percentage price preference into selected federal procurement guidelines and to provide direct percentage subsidies to consumcrs of spccified recycled materials.

Any such subsidies, however, must not go bcyond the principal objective of government policy: cstablishing cconomically viable and environmentally sound recycling industries. Recycling, like disposal and other resourcc recovery tcchnologics, uses resources and contributes to pollution. Therefore, these subsidies should be carefully monitored and adjusted so as to prevent onc cnvironmentally and cconomically wasteful set of disposal and resource recovery technologies from being replaced with another.

\subsection{Encouraging environmentally sound purchasing and disposal decisions by households 28}

Fcderal governments should also implcment policics dcsigned to cnsure that households recognize and respond to the cnvironmental tradeoffs inherent in purchasing and disposal decisions. Since the mix of resource recovery and disposal options will vary significantly from community to community, local governments should have primary authority for choosing the appropriate incentive-based policy tailored to the specific attributes and values of their communities ${ }^{29}$ Nonetheless, federal governments have an important role to play in efficiently gathering the information necessary to implement disposal surcharges, guiding local communities in choosing and designing regulatory policies, and educating consumers about environmentally responsible purchasing and disposal.

\subsubsection{Establishing a database for disposal surchages}

A major impediment to implementing the disposal surcharge policy is establishing a database of the refuse materials contained in consumer products. For any one community, this task would be daunting. It is doubtful that product manufacturers would bc willing to provide a breakdown of the disposable materials in their products to one or a few local governments. Moreover, the costs of assembling and updating this database would overwhelm the budgets of even large communities.

Given the national scope of product markcts and the economies of scale in establishing a product composition database, federal governments are best situated to require manufacturers to disclose the composition of disposable matcrials in their products and

\footnotetext{
28 Many of the policy rccommendations offered here are discussed more extensively in Menell, supra note 13 .

${ }^{29}$ It is possible that uniform federal product charges would be more cost-effective than a decentralized system because of economies of scale in production and implementation. See Begley, The Supply-Side Theory of Garbage, Newsweek 76 (Nov. 27, 1989) (describing a proposal by the Environmental Defense Fund for a national sales tax on some disposable products). Given the heterogeneity of local disposal costs and other factors, however, it is unlikely that such economies would outweigh the benefits of better-tailored local regulatory programs. As cvidenced by the use of local bottling companies and regional variation in product packaging by many national inanufacturers, the efficient scale of operation for most production facilities is relatively small. The only area in which there are significant national economies of scale are in advertising and trademark. lt is not at all clear, however, that such activities would be significantly affected by variation in product packaging incentives across regions.
} 
packaging and assemble a computerized database containing this information. Manufacturers should be required to disclose the weight and volume of the major categories of disposable materials in each product. Federal regulatory authorities could then prepare a computer file matched to the Universal Product Code that would cnable municipalities to establish appropriate disposal surcharges simply by entering data on the expected social disposal costs of the various disposable materials.

\subsubsection{Guiding community incentive-based policies and consumer education}

Local communities will also encounter difficulties in determining the social costs that should be reflected in curbside and retail disposal charges. In a community utilizing landfill, incineration, and resource recovery technologies, the following costs, among others, would have to be computed: the long-term environmental costs of disposing each type of material in landfills, the net social costs of incincrating each type of material, and the net social costs of resource recovery technologies. Careful assessment of these costs is beyond the capacity of even large local governments.

In view of the economies of scale in conducting this research, fcderal cnvironmental authorities should assemble the data necessary for local governments to design incentivebased regulatory policies. This data should be put into a computer system (and a reference book of social cost tables) that would enable local governments to generate appropriate charge parameters simply by entering data on relevant community-specific variables such as separation rates for waste stream components, refuse collection costs, land costs (for landfill and incineration facilities), groundwater characteristics, population density near disposal facilities, and air flow patterns. In addition, federal environmental authorities should conduct research on improved monitoring technologies for solid waste management such as refuse removal vehicles and billing systcms.

In concert with its advising on the choice of disposal and resource recovery technologies, federal environmental authorities should also advise local governments on how to establish and operate incentive-based systcms. In addition, federal and regional authorities can play an important role in coordinating the usc of economic incentive systems among communities. Federal authorities can promote the use of these systems and develop their own expertise by funding a varicty of pilot programs.

By making the environmental costs of purchasing and disposal decisions apparent, economic incentive systems will help to educate consumers about how to conserve the environment. Federal governments should also play a direct role in educating consumers about cnvironmentally responsible purchasing and disposal. First, federal governments should require all federal offices to establish waste separation programs. In addition, federal offices should adopt cost-cffective ways of reducing the amount of materials used.

Sccondly, fcderal governments should develop guidelines for truth in advertising regarding the environmental effects of consumer products. Many manufacturers are currently making questionable, if not fallacious, environmental claims for their products. For example, the assertion that biodegradable packaging is good for the cnvironment is highly misleading. As was discussed earlier, however, the environmental costs of different materials vary significantly according to how and where they are disposed.

Certain types of labeling are uncontroversial and standards should be expeditiously implemented. Standardized designations for different plastic resins, as are already being 
encouraged by the plastics industries, will enable households and waste processors to separate scrap plastics into uniform types for recycling. Standardized designations of the content of recycled materials will aid consumers who wish to favor the use of recycled materials.

More general designations of the environmental impact of particular materials are more complicated. Due to the heterogeneity of environmental costs across communities, national certifications of environmentally safe products are unlikely to be reliable. For example, clean plastics (i. e., made without heavy metal inks or other toxic materials) may be more environmentally sound in communities using incineration than glass which, if not recycled, will reduce the efficiency of combustion. On the other hand, unregulated labeling will permit misleading advertising. The best information will be reflected through the use of incentive-based regulatory systems at the local level. Thus, federal labeling guidelines should be designed to complement these price signals.

\section{Conclusions}

When households purchase retail products, they typically pay an amount approximating the social cost of producing such products. Yet they are often free to dispose of the empty container or packaging as they wish, incurring no cost. As growing municipal solid waste problems have made many communities painfully aware, however, disposal is far from free. This Article has argued that economic incentive approaches provide an efficacious means of systematically addressing the underlying causes of municipal solid waste problems. In essence, they ensure that households bear a feasible approximation the full costs of their purchasing and disposal decisions.

The challenge of using economic incentive approaches to regulate municipal solid waste lies in balancing the advantages of proper pricing of waste disposal and resource recovery with the administrative costs of such pricing systems. Due to the heterogeneity of the factors determining the best mix of disposal and recovery techniques as well as the variety of factors affecting the composition of the waste stream, incentive systems should be tailored to local conditions. Nonetheless, federal governments have significant roles to play in guiding communities toward effective incentive-based policies. 